\title{
REGULAÇÃO JURÍDICA, POLÍTICAS PÚBLICAS MUNICIPAIS E RESPONSABILIDADE SOCIAL DAS EMPRESAS
}

\author{
LEGAL REGULATION, MUNICIPAL PUBLIC POLICIES AND \\ COMPANIES' SOCIAL RESPONSIBILITY
}

\author{
Saulo de Tarso Silvestre Sanhueza Manriquez" \\ Fabiane Lopes Bueno Netto Bessa**
}

\begin{abstract}
Resumo: Estudo que se propõe a analisar as interações entre a regulação jurídica (como forma de atuação do Estado que enfatiza a indução de comportamentos), a responsabilidade social das empresas (como movimento que propõe a discussão do papel das empresas na atualidade, e de desenvolvimento de instrumentos de auto-regulação do mercado, voltados à mudança dos atuais modelos de produção e consumo) e a cidade como primeiro espaço de pertencimento cívico e, por isso mesmo, como local privilegiado para a integração de políticas públicas e iniciativas da sociedade e do mercado em direção a uma sociedade mais sustentável.
\end{abstract}

Palavras-chave: Desenvolvimento sustentável. Regulação jurídica. Políticas públicas. Responsabilidade social das empresas. Cidades.

\begin{abstract}
This study aims at analyzing the interactions between legal regulation (as a way of State performance that emphasizes the induction of behaviors), the companies' social responsibility (as a movement that proposes the discussion of the companies' current role, and development of self-regulatory instruments of the market aimed at changing the present production and consumption model) and the city as the first space of civic belonging and, therefore, as a privileged place for the integration
\end{abstract}

Bolsista PIBIC/CNPq do Curso de Direito da Pontifícia Universidade Católica do Paraná, integrante do projeto de pesquisa Desenvolvimento Sustentável, Responsabilidade Social das Empresas e Cidades. email: lidknorpel@yahoo.com.br Doutora em Direito das Relações Sociais (UFPR), Mestre em Direito Público (UFPR), professora do Programa de Pós-Graduação em Direito Econômico e Socioambiental da PUC-Paraná, professora convidada do ISAE-FGV, coordenadora do projeto de pesquisa Desenvolvimento Sustentável, Responsabilidade Social das Empresas e Cidades, procuradora licenciada e ex-diretora da Escola Superior da Procuradoria da Fazenda Nacional no Paraná. email: fabiane.bessa@uol.com.br. 
Saulo de Tarso Silvestre Sanhueza Manriquez; Fabiane Lopes Bueno Netto Bessa

between public policies and initiatives by the society and the market towards a more sustainable society.

Keywords: Sustainable development. Legal regulation. Public policies. Companies' social responsibility. Cities.

\section{INTRODUÇÃO}

A cidade é o primeiro núcleo de pertencimento político e social, em torno do qual orbitam as atividades industriais, comerciais, financeiras e de prestação de serviços - tornando-se local privilegiado de crescimento econômico, de concentração de serviços públicos (hospitais, universidades, etc.) e, em alguns casos, conseqüentemente, forte núcleo de atração migratória. É nela que se exercem os direitos e se cumprem os deveres: onde se constrói a cidadania.

Alertando sobre a crescente importância das questões urbanas, como tópico essencial na abordagem do desenvolvimento humano em termos globais, e registrando que, em 1990, das trinta maiores metrópoles mundiais vinte estavam em países subdesenvolvidos (entre os quais, a Índia, China, Paquistão, Brasil e México) a Conferência Mundial das Nações Unidas sobre os Assentamentos Humanos, (Habitat II - Istambul) ocorrida em 1996, e o Relatório sobre o Desenvolvimento Humano elaborado no mesmo ano pelo Programa das Nações Unidas para o Desenvolvimento (PNUD) - estimaram que em 2025, o percentual de habitantes em assentamentos humanos urbanos (que em 1975 era de 37,73\% da população mundial) ultrapassaria os 61,07\%. A projeção para o Brasil, segundo este estudo, é de que em 2020, 88,94\% da população viverá em centros urbanos.

Assim, os impactos ambientais (poluição do ar, sonora, visual), sociais (violência urbana, déficit habitacional, alta concentração de desempregados e de demandas por serviços e equipamentos públicos) e econômicos (concorrência entre cidades, guerras fiscais, influência do poder econômico nas políticas públicas) que hoje são realidades do meio urbano, poderão se estender a $61 \%$ da população mundial e quase $90 \%$ da população brasileira - como conseqüências das políticas públicas, da regulação econômica e da articulação (ou desarticulação) dos esforços voltados ao desenvolvimento sustentável, por parte dos governos, do mercado e da sociedade civil.

A abordagem dessas questões vem ganhando força nas últimas décadas, em virtude do aumento prodigioso da população urbana, bem como pela crise do modelo econômico baseado no uso de matrizes energéticas não renováveis e no desrespeito ao meio ambiente e à dignidade da pessoa humana, por parte de uma 
Regulação jurídica, políticas públicas municipais e responsabilidade social das empresas

parcela significativa de agentes econômicos e mesmo do Poder Público ${ }^{1}$ justificando-se, assim, o estudo e a reflexão sobre as relações entre a atuação empresarial e as políticas públicas municipais na promoção do desenvolvimento sustentável.

A questão ambiental, que começou a ser discutida internacionalmente da década de 70 do século que há pouco se encerrou, teve como um de seus principais marcos a Conferência ocorrida em 1992 no Rio de Janeiro, cujo tema central foi o desenvolvimento sustentável e que teve como um de seus principais documentos a Agenda 21. Esta foi o ponto de partida para a formulação das Agendas $21^{2}$ nacionais, estaduais e municipais. No caso do Brasil, a questão do desenvolvimento sustentável pensado sob o ponto de vista das cidades foi um entre os 6 temas da Agenda 21 Brasileira: Cidades Sustentáveis - que traduz, inclusive, a perspectiva mundial de enfrentamento da questão: "pensar globalmente, agir localmente"3.

Entre as premissas definidas para o desenvolvimento deste tema estão: diálogo entre a Agenda 21 brasileira e as atuais opções de desenvolvimento, gestão integrada e participativa, foco na ação local, mudança do enfoque das políticas de desenvolvimento e preservação ambiental (substituição gradual de instrumentos de caráter punitivo por instrumentos de incentivo e auto-regulação dos agentes sociais e econômicos) e informação para a tomada de decisão.

Considerando que a própria idéia de desenvolvimento sustentável vincula-se, conforme mais adiante será analisado, ao atendimento a pelo menos três aspectos - o econômico, o social e o ambiental - sua promoção pressupõe a atuação integrada entre $\mathrm{C}$, e sua abordagem deve ser multidisciplinar, pois, com bem observa Lopes (2001, p. 15): "Nenhum dos problemas concretos que na vida real se imponham é de ordem estritamente disciplinar; apenas por razões de arrumação e de simplificação, o conhecimento tem sido academicamente compartimentado.”

${ }^{1}$ Uma vez que, a exemplo das grandes hidrelétricas (e não obstante os aspectos positivos que também apresentam), muitos dos grandes projetos de forte impacto social e ambiental são desenvolvidos pelo Poder Público.

${ }^{2}$ Documento aprovado pela Conferência das Nações Unidas sobre Meio Ambiente e Desenvolvimento - também denominada Eco/92 que traduz o compromisso das nações para mudança do padrão de desenvolvimento no século XXI. Por sua vez, cada país desenvolveu suas agendas nacionais e, no caso de estados federais - como o Brasil - a proposta é de que cada Estado-membro e cada Município desenvolva sua própria Agenda 21.

3 Segundo Ana Luiza Camargo (2003) a expressão é atribuída a Hazel Handerson, economista que desenvolve estudos do futuro e autora de diversos livros entre os quais "Além da Globalização" e "Transcendendo a Economia". 
Saulo de Tarso Silvestre Sanhueza Manriquez; Fabiane Lopes Bueno Netto Bessa

Portanto, a construção de um Direito dinâmico e harmônico com a evolução social, deve necessariamente beber em fontes outras que não a própria, sob pena do ordenamento jurídico se ver esvaziado em sua retórica, distanciando-se cada vez mais da realidade social.

\section{REGULAÇÃO JURÍdicA, POLÍTICAS PÚBLICAS MUNICIPAIS E DESENVOLVIMENTO SUSTENTÁVEL}

Identificar os pontos comuns ou complementares entre a atuação do Estado, das empresas e da sociedade num esforço de coordenado de promoção do desenvolvimento sustentável é o ponto central deste estudo.

Para tanto, faz-se necessária a prévia estruturação das bases conceituais que permeiam tal reflexão, razão porque se mostra essencial o entendimento dos temas que lhe dão suporte: desenvolvimento sustentável, regulação jurídica, políticas públicas, competência municipal e responsabilidade social das empresas - os quais serão objeto de estudo no desenvolvimento deste trabalho.

\section{1 desenvolvimento, sustentabilidade, desenvolvimento sustentável}

Existem várias teorias que visam estabelecer um marco conceitual sobre o termo desenvolvimento.

Veiga (2005) observa que dentre elas, destacam-se as que consideram o desenvolvimento uma ilusão, uma quimera. Uma das expressões desse pensamento é o sociólogo italiano Giovani Arrighi, que vê com bastante ceticismo a possibilidade de mobilidade ascendente na rígida economia capitalista, considerando irrisórias as chances dos países periféricos (pobres) elevarem-se ao nível dos países semiperiféricos (emergentes) e estes ao nível dos países centrais (ricos). Outro autor que adota entendimento semelhante é Celso Furtado na sua obra "O mito do desenvolvimento econômico", cujo cerne, segundo Veiga (2005, p. 28) é a irrefutabilidade de "que as economias periféricas nunca serão desenvolvidas, no sentido de similares às economias que formam o centro do sistema capitalista".

A maneira mais comum e antiga de entender o desenvolvimento é aquela que o associa ao crescimento econômico, ou que simplesmente trata ambos como sinônimos. Nesse sentido, observa Veiga (2005, p. 19):

Até o início dos anos 1960, não se sentiu muito a necessidade de distinguir desenvolvimento de crescimento econômico, pois as poucas nações desenvolvidas eram as que se haviam tornado ricas pela industrialização. De outro lado, os países que haviam permanecido no subdesenvolvimento eram os pobres, nos quais o processo de industrialização era incipiente ou nem havia começado. Todavia, foram 
Regulação jurídica, políticas públicas municipais e responsabilidade social das empresas

surgindo evidências de que o intenso crescimento econômico, ocorrido durante a década de 1950 em diversos países semi-industrializados (entre os quais o Brasil), não se traduziu necessariamente em maior acesso de populações pobres a bens materiais e culturais, como ocorrera nos países considerados desenvolvidos. A começar pelo acesso à saúde e à educação. Foi assim que surgiu o intenso debate internacional sobre o sentido do vocábulo desenvolvimento. Uma controvérsia que ainda não terminou, mas que sofreu um óbvio abalo esclarecedor, desde que a ONU passou a divulgar anualmente um índice de desenvolvimento que não se resume à renda per capita ou à renda por trabalhador.

O advento do Índice de Desenvolvimento Humano (IDH), em 1990, significou uma ruptura nos critérios de aferição de desenvolvimento, haja vista que o descaracteriza como sinônimo de crescimento econômico, na medida em que avalia três critérios, a saber: educação, renda e longevidade, passando com isso o crescimento econômico, a ser entendido por muitos estudiosos do tema, como um meio de serventia ao desenvolvimento.

Pode-se dizer que o IDH traz no seu bojo a idéia de crescimento, posto que o critério "renda", é calculado com base no PIB per capita, mas, na medida em que avalia os critérios da educação ${ }^{4}$ e da longevidade ${ }^{5}$, impede que o crescimento seja tomado por sinônimo de desenvolvimento.

O crescimento deve vir acompanhado de um aumento na esperança de vida da população, de um baixo índice de mortalidade infantil e de bons níveis de saúde e salubridade para todo o corpo social avaliado ${ }^{6}$ pois, como bem observa Amartya Sen (2000, p. 29): "o crescimento econômico não pode sensatamente ser considerado um fim em si mesmo”.

Essa concepção não é nova: riqueza, relações comerciais e dinheiro, sempre foram objetos de ponderação ao longo da história da humanidade. Um exemplo disso é o pensamento aristotélico que entende que "[...] a riqueza não é, obviamente, o bem que procuramos: trata-se de uma coisa útil, nada mais, e desejada no interesse de outra coisa" (ARISTÓTELES, 2002, p. 22).

$\mathrm{O}$ que seria, então, o desenvolvimento? Entendendo que o desenvolvimento deve estar associado à ampliação das liberdades individuais substantivas ${ }^{7}$, Sen

${ }^{4}$ No critério educação é avaliada a taxa de alfabetização, bem como o somatório de pessoas que freqüentam cursos de nível fundamental, médio, superior, cursos supletivos e pós-graduação.

${ }^{5}$ Nesse critério é avaliada a expectativa de vida da população observada, as condições de saúde e salubridade do local e taxa de mortalidade infantil.

${ }^{6}$ Diz-se corpo social avaliado pois o IDH pode ser avaliado no âmbito nacional, estadual ou municipal. 
Saulo de Tarso Silvestre Sanhueza Manriquez; Fabiane Lopes Bueno Netto Bessa

frisa que a privação de liberdade que uma pessoa pode sofrer não se resume ao cerceamento das liberdades políticas e direitos políticos (tais como a liberdade de expressão, liberdade de culto, direito ao sufrágio, direito ao devido processo legal com ampla defesa e contraditório), mas se estende a todo um corpo de necessidades básicas dos seres humanos, as quais, quando não atendidas redundam em privação de liberdade.

Assim, em sintonia com o pensamento de Sen, pode-se considerar que o desenvolvimento implica fazer correr concomitantemente com o crescimento econômico um projeto de promoção da melhoria da qualidade de vida de toda uma sociedade, aplacando a miséria, tutelando e promovendo os direitos humanos, ampliando as liberdades humanas substantivas, aprimorando o sistema democrático e todas as suas instituições.

Feitas essas observações acerca do desenvolvimento, passa-se à abordagem de seu elemento complementar (e portanto, não antinômico): a sustentabilidade.

A idéia de sustentabilidade implica segundo Veiga (2005, p. 171), no "duplo imperativo ético de solidariedade sincrônica com a geração atual e de solidariedade diacrônica com as gerações futuras.”

Os objetivos da sustentabilidade, de acordo com o autor, seriam:

1) preservação do potencial da natureza para a produção de recursos renováveis; 2) limitação do uso dos recursos não renováveis; respeito e realce para a capacidade de autodepuração dos ecossistemas naturais. [...]

Ela impele ainda a buscar soluções triplamente vencedoras (Isto é, em termos sociais, econômicos e ecológicos), eliminando o crescimento selvagem obtido ao custo de elevadas externalidades negativas, tanto sociais quanto ambientais (VEIGA, 2005, p. 171-2).

O desenvolvimento sustentável por sua vez, pressupõe o equilíbrio harmônico entre o desenvolvimento (entendido sob o prisma de Amartya Sen) e a sustentabilidade (a partir da postura moderada de José Eli da Veiga) - e traduz a perspectiva trazida pelo Relatório Bruntland ${ }^{8}$ o qual propõe que a sustentabilidade ecológica e o desenvolvimento econômico são desejáveis e possíveis, não havendo, portanto, contradição entre eles (ALTVATER, 1999).

${ }^{7}$ É de observar que o pensamento de Sen tangencia em vários aspectos o conteúdo avaliatório do IDH, até porque ele é um dos seus idealizadores.

${ }^{8}$ Documento que resultou da primeira conferência da ONU tratando sobre meio ambiente, ocorrida em 1972 na Cidade de Estocolmo, e que levou este nome em homenagem à primeira Ministra da Suécia Gros Bruntland que teve participação fundamental nos trabalhos. 
Regulação jurídica, políticas públicas municipais e responsabilidade social das empresas

A idéia de desenvolvimento sustentável traz no seu bojo o reconhecimento das empresas como atoras fundamentais - haja vista que a mudança nos modelos de produção e consumo atuais está no cerne das questões envolvendo o tema. Tem início, então, uma outra discussão, agora quanto à Responsabilidade Social das Empresas (RSE), e a necessidade de uma interação entre políticas públicas, mecanismos regulatórios do Estado e instrumentos auto-regulatórios de mercado, como forma de catalisar esforços em direção ao desenvolvimento sustentável.

\subsection{Desenvolvimento sustentável e atividade empresarial}

Se as organizações representam instrumentos de geração de trabalho, renda, bem-estar social, desenvolvimento e até mesmo felicidade, elas podem por outro lado, "[...] acarretar danos reais e diretos, de natureza física, social e mental à sociedade" (HALL, 2004, p. 12), o que, inexoravelmente às conduzem a um desvio de sua finalidade social.

Os danos a que as organizações privadas podem dar causa se dão, entre outros motivos, por desconhecimento de suas ações (falta de informações e/ou orientações técnicas); pela omissão; pela má-fé que a conduz a práticas dolosas em prol de ganhos imediatos; ou pelas relações promíscuas que mantêm com o poder público.

Nesse sentido tem-se a sempre atual afirmação do filósofo Mário Ferreira dos Santos (1962, p. 28-9):

Se alguns apenas se satisfazem em ganhar seus lucros, e deles tirar o melhor proveito, outros desejam dominar, superar, vencer os adversários e concorrentes, liquidandoos, humilhando-os, ou ainda, pretendem assegurar lucros pelos meios mais seguros, como sejam os que podem propiciar o monopólio concedido pelo governo, e defendido e amparado pela força do Estado.

Fica subentendida no pensamento acima exposto, a figura do empresário, do gestor. Nesta toada, os danos causados ao meio ambiente (a poluição, a eliminação de lixo tóxico, a destruição de ecossistemas, etc.), às relações de trabalho (como por exemplo, a sujeição do trabalhador a ambientes de trabalho insalubres ou a constantes riscos de acidentes), à livre concorrência (tais como dumping ou privilégios obtidos sob aliciamento de membros do poder público), não são em si atos econômicos, mas atos antiéticos que se dão no campo da economia, e são, portanto de origem extra-econômica. Assim, dizem respeito, também, à mentalidade das pessoas que conduzem a atividade empresarial, muito embora seja a pessoa jurídica (a sociedade empresária), convencionalmente, a responsável por suas ações e omissões. 
Saulo de Tarso Silvestre Sanhueza Manriquez; Fabiane Lopes Bueno Netto Bessa

Entretanto, o fundo motor de uma atividade lesiva pode ser de ordem eminentemente econômica, uma vez que as empresas estão inseridas inevitavelmente no mercado, no qual lutam por seus interesses - e até por sua sobrevivência. É o que acontece quando muitas organizações vêem-se obrigadas, em virtude da dinâmica das relações mercadológicas, a tomarem medidas drásticas para manterem-se competitivas, como é o caso das ondas recentes de

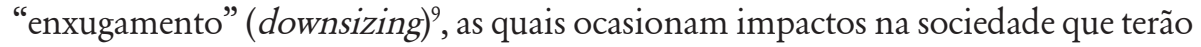
efeitos imprevisíveis durante muito tempo.

As organizações têm o poder de mexer com a cultura, os valores e o modo de vida de indivíduos e até mesmo de povos (BESSA, 2006), e quanto maior o empreendimento, maior o impacto que ele produz. Elas são núcleos de poder, e, por exemplo, em virtude do lobby praticado por algumas delas, já há quem diga, como é o caso de Hall (2004, p. 12) que elas podem “[...] ser consideradas como uma fonte de leis".

Assim, a responsabilidade social a partir das empresas passa pela individualidade dos gestores e pela soma destas mesmas individualidades traduzidas em linguagem auto-regulatória do mercado.

Da individualidade do gestor empresarial e de cada membro que compõem a cúpula decisória de uma empresa forma-se a cultura organizacional. A influência desta sobre outras organizações, pode levar concentricamente, à um modelo de atuação que passa a ser exigido de todos os que atuam em determinado mercado e este fenômeno é de sensível importância no âmbito da Responsabilidade Social das Empresas.

Um exemplo disso é o fato de já existirem, hoje, algumas empresas brasileiras que se responsabilizam, espontaneamente, por todo o ciclo de seu produto, o que consiste numa expressão natural de responsabilidade social, haja vista que no Brasil não há exigência legal, nesse sentido. Diante disso, o mercado, absorvendo esses tipos de cultura, as traduz, de modo gradativo, em exigência comum a todos os agentes econômicos privados. Nesse sentido, a responsabilidade social empresarial passa a abranger toda a cadeia de relacionamentos, abrangendo os trabalhadores, os consumidores, os fornecedores, o Estado, os acionistas, o meio ambiente, os concorrentes e a sociedade tomada como um todo: é o chamado stakeholder capitalism.

A conscientização empresarial acerca da sustentabilidade vem se ampliando paulatinamente, mas como sua evolução natural depende de mentalidades, não é

${ }^{9}$ Infelizmente essa não é para muitas empresas a medida última de saneamento financeiro, ou seja: o primeiro corte de custos é o corte de pessoal. 
Regulação jurídica, políticas públicas municipais e responsabilidade social das empresas

suficiente esperar que todo o meio empresarial torne-se consciente de seu papel e atue no sentido de colaborar para o desenvolvimento sustentável, o que revela a necessidade de intervenção do Estado no domínio econômico, conforme será analisado no tópico que segue.

\subsection{Direito econômico e regulação jurídica}

Washington Peluso Albino de Souza (1999, p. 27) define Direito Econômico como sendo:

[...] o ramo do Direito que tem por objeto a juridicização, ou seja, o tratamento jurídico da política econômica e, por sujeito, o agente que dela participe. Como tal, é um conjunto de normas de conteúdo econômico que assegura a defesa e harmonia dos interesses individuais e coletivos, de acordo com a ideologia adotada na ordem jurídica.

O conceito descrito aponta para uma visão moderna do Direito Econômico, que o encara como um ramo autônomo do Direito, com regras, princípios, normas e objeto próprios.

O Direito Econômico dita o "dever-ser” para as atividades econômicas, sejam elas estatais ou privadas e regula a política econômica de produção e circulação de bens e o consumo (CLARK, 2001, p. 7).

A intervenção estatal no domínio econômico, hodiernamente, pode ser justificada em virtude da contenção de crises, ou para evitá-las; para fomentar o avanço de setores estratégicos; para solucionar problemas de desemprego estrutural; para combater as disparidades regionais; bem como, para promover o desenvolvimento sustentável.

Diversas são as modalidades de intervenção do Estado na economia, a saber: 1) orientadora, quando Estado orienta os agentes privados a atuarem de certa maneira, para que alcancem objetivos específicos, sem a presença de comandos normativos coatores ou proibitivos, mas sim incentivando a iniciativa privada, por exemplo, com prêmios e isenções tributárias. 2) dirigida, na qual, há por parte do Estado a edição de normas que proíbem ou determinam uma conduta ativa ou negativa (omissão) aos particulares e aos atores econômicos estatais; 3 ) combinada, na qual o Estado ao lado dos particulares - empresários, trabalhadores, consumidores, profissionais liberais, ambientalistas -, mediados por suas entidades representativas estabelecem diretrizes às atuações conjuntas ou individuais; 4) contratual, na qual o Estado e os particulares celebram contratos para a concretização dos objetivos da intervenção. Aqui os particulares buscam, pela via contratual, vantagens e facilidades em troca ajudarem o Estado na promoção do bem-estar social (CLARK, 2001, p. 31-2). 
Saulo de Tarso Silvestre Sanhueza Manriquez; Fabiane Lopes Bueno Netto Bessa

Vale destacar ainda, que pela clássica divisão de Bernard Chenot do Direito Econômico em Direito Regulamentar Econômico e Direito Institucional Econômico, a intervenção pode ainda ser classificada, como "direta", "indireta" e "mista”. A direta, dá-se com a criação de empresas estatais (empresas públicas e sociedades de economia mista) pelo Estado, para atuarem no domínio econômico, ou como agentes no âmbito da livre concorrência com os particulares, ou de modo monopolístico; ou ainda, quando o Estado cria as agências reguladoras para regularem e fiscalizarem serviços e atividades econômicas. A intervenção indireta ou Direito Regulamentar Econômico, dá-se pela expedição de normas jurídicas (leis, medidas provisórias, portarias, circulares, resoluções, instruções normativas), advindas dos Poderes Legislativo e Executivo (CLARK, 2001, p. 33).

Ao Município é possível intervir em qualquer uma das modalidades de intervenção acima referidas, como a seguir será explicitado.

\subsection{Regulação jurídica e políticas públicas no âmbito municipal}

O Brasil, a despeito de ser um Estado Federal, ainda possui uma inegável tendência ao centralismo, que acaba sobrecarregando a sociedade brasileira com um pesado fardo: o déficit democrático, em virtude de ser na Comuna ${ }^{10}$ que a maior parte das demandas da cidadania podem ser atendidas, ao ponto de Clark (2001, p. 149-150) atribuir ao federalismo brasileiro um caráter perverso, "bem perto de um Estado unitário centralizador”.

Entretanto, não se pode negar os avanços ocorridos, particularmente nas últimas décadas, com o advento da Constituição Federal promulgada em 05 de outubro de 1988. Nesse sentido, Bonavides (2006, p.344) observa que: "As prescrições do novo estatuto fundamental de 1988 a respeito da autonomia municipal configuram indubitavelmente o mais considerável avanço de proteção e abrangência já recebido por esse instituto em todas as épocas constitucionais de nossa história.”

A Carta Magna de 1988 elevou o Município à qualidade de ente integrante ${ }^{11}$ da Federação, dotado de autonomia política, administrativa e financeira, conforme previsto nos artigos 29, 30,31, 156, 158 e 159, mas manteve a perspectiva de cooperação entre os integrantes da Federação. O critério de repartição de competências utilizado pela Carta Magna, conforme aduz Jair Eduardo Santana

${ }^{10} \mathrm{O}$ termo Comuna é sinônimo de Município e é comumente usado pelos municipalistas.

${ }^{11}$ Vale ressaltar que há autores, como é o caso de Alexandre de Moraes (2006, p. 206) que consideram o município como sendo entidade federativa e não apenas ente integrante da federação. 
Regulação jurídica, políticas públicas municipais e responsabilidade social das empresas

(1998, p. 46), é de que "Competem ao poder central os poderes enumerados pela própria Constituição, aos Estados-Membros tocam os poderes residuais e, aos Municípios, aqueles poderes inerentes a sua autonomia para dispor sobre tudo que diga respeito ao seu interesse local”.

O interesse local, disposto no art. 30, I da Constituição de 88, é corolário das atribuições que compõem a sua autonomia, e, segundo Meirelles (2003, p. 134), "[...] se caracteriza pela predominância (e não pela exclusividade) do interesse do Município em relação ao Estado e à União”.

Assim, a Constituição de 88 deu ao município competências próprias em algumas matérias (art.30) e comuns com a União, os Estados e o Distrito Federal em outras (art.23).

Há, no entanto, quem entenda - como é caso de Jair Santana (1998, p. 136) que há no âmbito municipal as competências ditas concorrentes, mesmo a despeito de não constar o município no rol do art. 24 da Carta Magna. Esse entendimento só é possível a partir de uma interpretação extensiva do art. 30, II da Constituição, que diz "que cabe ao Município suplementar a legislação federal e a estadual no que couber”. Essa competência concorrente não seria apenas administrativaregulamentar, estando, portanto, os municípios autorizados a legislar suplementarmente, ou seja, suprindo a falta da legislação federal ou estadual até o advento das leis editadas pelas respectivas esferas, e complementando a lei existente para que melhor sejam atendidas as especificidades locais.

A repartição de competências apresenta reflexos, igualmente, na formulação de políticas públicas municipais. Estas, nas palavras de Bucci (2002, p. 241) são "programas de ação governamental visando a coordenar os meios à disposição do Estado e as atividades privadas, para a realização de objetivos socialmente relevantes e politicamente determinados".

As diretrizes de uma política pública, via de regra, são elaboradas pelo Poder Legislativo e executadas pelo Poder Executivo.

Na promoção da responsabilidade social das empresas, e em harmonia com a Carta Magna, dois modelos de atuação do Estado podem ser adotados: o propulsor (centrado nos programas finalísticos) e o incitador (que instiga, combinando normas e persuasão), os quais, segundo Clark, também se aplicam no âmbito municipal, de modo que, como explica o autor:

As normas de Direito Econômico editadas no âmbito municipal nem sempre precisam ser proibitivas (vedar determinado comportamento econômico) ou imperativas (ordenar certo comportamento econômico), mas podem ser, de acordo com as peculiaridades das normas do referido ramo, programáticas (orientam para determinado fim a ser atingido), premiais (estabelecem prêmios, incentivos, estímulos 
Saulo de Tarso Silvestre Sanhueza Manriquez; Fabiane Lopes Bueno Netto Bessa

para aqueles que a aderirem, não prevendo qualquer sanção para os agentes que optem por outro comportamento) ou objetivas (estabelecem objetivos quantitativos para se cumprirem as metas traçadas). No âmbito local, todos esses tipos de normas podem ser confeccionadas, independentemente das normas estaduais e federais, para regulamentar as políticas econômicas dos seus agentes (CLARK, 2001, p. 11).

Acerca do Estado propulsor, sob o prisma municipal, destaca Meirelles (2003, p. 486), que o poder de propulsão:

[...] é a faculdade de que dispõe o Município para impulsionar o desenvolvimento local, através de medidas governamentais de sua alçada. É, pois, toda ação incentivadora de atividades particulares lícitas e convenientes à coletividade. Fomentar o desenvolvimento econômico, cultural e social dos munícipes é missão tão relevante quanto à contenção de atividades nocivas à coletividade.

Para atuar de modo propulsor, o Município pode fazer uso de diferentes instrumentos, tais como as isenções. Se o Município, dentro do que lhe confere o art. 156 da Constituição Federal, possui aptidão para tributar, possui ele também a faculdade de isentar, ambas sujeitas ao princípio da legalidade (artigos 5ª , II, e 150, I, da Constituição Federal).

As isenções podem ser condicionais ou incondicionais. As isenções condicionais figuram entre os instrumentos a disposição do Município para a promoção da responsabilidade social das empresas afinal, segundo Carraza (2006, p. 846): “[...] para serem fruídas, exigem uma contraprestação do beneficiário. Ele é que deve decidir se vale, ou não, a pena fruir desta vantagem. Bastará, para tanto, que preencha, ou não, os requisitos apontados na norma isentiva.” As isenções condicionais, não implicam portanto, em renúncia fiscal.

Além das isenções, tem-se ainda, como exemplo de política pública propulsora, a Lei Complementar 40 do Município de Curitiba, que dispõe sobre os tributos municipais, em especial o artigo 39, que prevê uma alíquota premial referente ao imposto sobre a propriedade predial e territorial urbana (IPTU) em função da utilização do imóvel, ou seja, em razão do cumprimento da função social da propriedade, e, conseqüentemente, da responsabilidade social das empresas.

\subsection{Regulação Jurídica e a Responsabilidade Social das Empresas}

Maria Dallari Bucci (2002, p. 66) observa que a "regulação diz respeito a todas as formas de intervenção ou interferência do Estado na vida dos cidadãos e das empresas", não se restringindo, portanto, a aspectos econômicos.

Sendo a empresa "um núcleo de múltiplas manifestações do direito de propriedade” (BESSA, 2006, p. 101) ela está sujeita aos contornos constitucionais da função social da propriedade (art. 5a , XXIII, da Constituição Federal) e, por 
Regulação jurídica, políticas públicas municipais e responsabilidade social das empresas

assim ser, deve atuar buscando o equilíbrio entre seus interesses e os anseios sociais: a responsabilidade social das empresas.

São inúmeras as formas de regulação jurídica que delineiam a responsabilidade social das empresas. Nesse sentido tem-se como exemplo de regulação jurídica voltada à estruturação do direito de vizinhança. O Estatuto da Cidade (Lei 10.257 de 10 de julho de 2001), em seus artigos 36 a 38 prevê o estudo de impacto de vizinhança, que é um "[...] instrumento para que se possa fazer a mediação entre os interesses privados dos empreendedores e o direito à qualidade urbana daqueles que moram ou transitam no seu entorno” (BRASIL, 2002, p. 198), haja vista que o zoneamento não é suficiente para solucionar todos os problemas de vizinhança.

O estudo de impacto de vizinhança tem por desiderato "[...] democratizar o sistema de tomada de decisões sobre os grandes empreendimentos a serem utilizados na cidade, dando voz a bairros e comunidades que estejam expostos aos impactos dos grandes empreendimentos” (BRASIL, 2002, p. 199).

Instrumentos análogos ao Estudo de Impacto de vizinhança são os estudos de impacto ambiental e a regulamentação de pólos geradores de tráfego.

Outro instrumento importante de regulação, embora ainda não exigido por lei (exceção feita ao Município de Porto Alegre), é o balanço social, o qual segundo Bessa (2006, p.197):

[...] constitui uma maneira de a empresa prestar contas aos seus diferentes interlocutores (clientes, fornecedores, empregados, governos, comunidade local, acionistas etc.) da utilização de recursos colocados à disposição da empresa - e que basicamente não lhe pertencem: os custos sociais, os fatores que a sociedade colocou ao serviço da empresa, recursos naturais etc.

A abordagem da regulação jurídica não pode prescindir da noção de poder de polícia, que, segundo Meirelles (2003, p. 448) “[...] não é um poder político, privativo dos órgãos constitucionais do Estado, mas sim um poder administrativo difundido entre toda a Administração Pública, na medida das necessidades de suas funções.” A polícia administrativa, deve atuar preferencialmente de forma preventiva, mediante ordens, proibições, ou por normas limitadoras e condicionadoras da conduta daqueles que utilizam bens ou exercem atividades que possam afetar a coletividade (MEIRELLES, 2003, p. 457).

No âmbito da competência municipal, merece atenção o poder de polícia relacionado às obras civis, implicando na necessidade do alvará de construção (que é uma autorização para construir de acordo com o projeto aprovado), o poder de polícia sanitária local (visando a higiene da cidade e ao abastecimento 
Saulo de Tarso Silvestre Sanhueza Manriquez; Fabiane Lopes Bueno Netto Bessa

de sua população - CF, art. 30, VII); o poder de polícia das águas (comum à União e aos Estados-membros, cabendo a cada um, dentro de suas competências estabelecer medidas sanitárias adequadas a manter as condições de uso da água). Dentro desse poder insere-se a repressão à poluição da água, traduzindo o zelo pela saúde e bem-estar da coletividade local e o poder de polícia do ar, que visa preservar o estado do ar respirável. Nesse sentido, o Decreto $\mathrm{n}^{\circ} 76.389$, de 3 / 10/1975, que regulamentou o Decreto-lei $n^{\circ} 1.413$ de 1975 , reafirmou (art.4 $4^{a}$ ) a competência municipal para controlar a poluição industrial, "respeitados os critérios, normas e padrões fixados pelo governo federal” (MEIRELLES , 2003, p. 470-1).

As sanções do poder polícia devem estar estabelecidas em lei ou regulamento. Elas servem como elemento de coação e intimidação e podem consistir em uma simples multa ou em penalidades mais severas como a interdição de atividade, a demolição de construção, o embargo administrativo de obra, a proibição de fabricação e/ou circulação de certos produtos, a vedação de localização de indústrias ou de comércio em determinadas zonas (MEIRELLES , 2003, p. 459).

A integração entre instrumentos regulatórios, instrumentos de auto-regulação do mercado (como certificações ambientais ou balanços sociais espontaneamente publicados pelas empresas) e o estímulo à participação da sociedade na formulação e controle de políticas públicas (através, por exemplo dos conselho municipais de políticas públicas) é de fundamental importância para a promoção da democracia participativa e, igualmente do desenvolvimento sustentável.

\section{CONCLUSÃO}

Evidenciados os fundamentos teóricos e as distinções existentes entre crescimento econômico, desenvolvimento, sustentabilidade e desenvolvimento sustentável, fica patente que este último é dotado de um maior juízo de plausibilidade, na medida em que a separação entre o desenvolvimento e a sustentabilidade ou gera melhoria da condição de vida da população às expensas do meio ambiente, o que, a longo prazo, anula a própria possibilidade de desenvolvimento pela não-renovação dos recursos naturais, ou gera a preservação $\mathrm{da}$ natureza às expensas da humanidade.

A promoção do desenvolvimento sustentável, em virtude da influência e abrangência das atividades das organizações privadas na contemporaneidade, passa necessariamente pela responsabilidade social das empresas.

A responsabilidade social das empresas insere-se necessariamente nos marcos regulatórios do Estado referentes à atividade empresarial. Em virtude disso, num primeiro momento, ela pode ser delineada simplesmente pelo respeito ao que o 
Regulação jurídica, políticas públicas municipais e responsabilidade social das empresas

ordenamento jurídico impõe, mas é evidente que o seu conteúdo teleológico vai muito adiante, passando da esfera normativa, para a esfera axiológica que informa concepção de empresa de um determinado gestor ou de uma determinada cultura organizacional.

A responsabilidade social das empresas pode nascer espontaneamente no próprio seio da atividade empresarial pela influência de uma determinada empresa num determinado mercado, de maneira tal que esta acaba por induzir os demais agentes privados a atuarem do mesmo modo, ou seja, fazendo com que o mercado traduza essa influência em linguagem auto-regulatória. Entretanto, na ausência da espontaneidade empresarial e/ou da auto-regulação voltada à promoção da responsabilidade social das empresas, ou mesmo concomitantemente, pode o Estado, pela intervenção no domínio econômico, exercer seu poder propulsor ou incitador mediante a criação de políticas públicas que conduzam e premiem a boa gestão.

Entretanto, seja na regulação ou na propulsão, o Poder Público, enfatizandose aqui o municipal, deve atuar em conformidade com os fundamentos, princípios e fins da ordem econômica brasileira (art. 170 da CF), de maneira tal que respeite a livre iniciativa, valorize o trabalho humano pelo combate ao desemprego e ao subemprego, defenda os consumidores e tutele o meio ambiente.

É de suma importância o conhecimento das realidades locais para o estabelecimento de políticas públicas, voltadas à promoção da responsabilidade social das empresas e do desenvolvimento sustentável, afinal "se os benefícios do desenvolvimento econômico-social devem ser para os indivíduos - todos os indivíduos - a localização deles é fator que não deve ser dispensado na análise e na adoção de políticas [...]” (LOPES, 2001, p. 4).

Este papel cabe à administração pública municipal e não a um corpo técnico da burocracia central da República, nem tampouco à ONGs internacionais ou a organismos internacionais que encaminham "pacotes de ações" a serem executadas, sem a devida transparência, pela Comuna. Cabe ao gestor municipal e aos vereadores de modo transparente e através de amplos diálogos com a população, estabelecer políticas públicas que estimulem ou premiem a responsabilidade social das empresas, a qual, inexoravelmente, deve compor toda e qualquer construção de modelos de desenvolvimento sustentável.

As políticas públicas voltadas à promoção da responsabilidade social das empresas podem e devem ser propostas pelo Poder Público Municipal, dentro da sua esfera de competência, através da adoção orquestrada de diferentes mecanismos típicos de Estado e a estimulação de mecanismos auto-regulatórios do mercado. 
Saulo de Tarso Silvestre Sanhueza Manriquez; Fabiane Lopes Bueno Netto Bessa

Muitos são os exemplos possíveis: arranjos de cooperação com empresas e sociedade civil que não detém um caráter predominantemente econômico, mas de uso de suas respectivas formas de atuação para promover a educação para o desenvolvimento sustentável no âmbito interno das entidades dos três setores; criação de prêmios (de natureza não financeira), que estimulem as empresas a apresentarem balanços sociais - como já fazem vários municípios brasileiros; especificação, em suas licitações, de produtos ambientalmente adequados, além do uso de mecanismos regulatórios tradicionais, como as isenções condicionais, dentro dos limites do art. 156 da CF 88, ou o estabelecimento de alíquotas premiais como é caso do artigo 39 da Lei Complementar 40 do Município de Curitiba.

\section{REFERÊNCIAS}

ALTVATER, Elmar. Os desafios da globalizaçã e da crise ecológica para o discurso da democracia e dos direitos Humanos. In: HELLER, Agmes et al. $A$ crise dos paradigmas em ciências sociais e os desafios para o século XXI. Rio de Janeiro: Contraponto, 1999. p. 107-147.

ARISTÓTELES. Ética a Nicômaco. São Paulo: Martin Claret, 2002.

BESSA, Fabiane Lopes Bueno Netto. Responsabilidade Social das Empresas: práticas sociais e regulação jurídica. Rio de Janeiro: Editora Lumen Juris, 2006.

BONAVIDES, Paulo. Curso de Direito Constitucional. São Paulo: Malheiros, 2006.

BRASIL. Estatuto da Cidade: guia para implementação pelos municípios e cidadãos: Lei n.10.257, de 10 de julho de 2001, que estabelece diretrizes gerais da política urbana. Brasília: Câmara dos Deputados, Coordenação de Publicações, 2002.

BUCCI, Maria Paula Dallari. Direito Administrativo e políticas públicas. São Paulo: Saraiva, 2002.

CARRAZA, Roque Antonio. Curso de Direito Constitucional Tributário. São Paulo: Malheiros, 2006.

CLARK, Giovani. O município em face do Direito Econômico. Belo Horizonte: Del Rey, 2001.

COSTA, Nelson Nery. Curso de Direito Municipal Brasileiro. Rio de Janeiro: Forense, 2000.

FOLADORI, Gillermo. Limites do desenvolvimento sustentável. São Paulo: Editora Unicamp, 2001. 
Regulação jurídica, políticas públicas municipais e responsabilidade social das empresas

HALL, Richard H. Organizações: estruturas processos e resultados. São Paulo: Prentice Hall, 2004.

LOPES, António Simões. Desenvolvimento regional. Lisboa: Fundação Calouste Gulbenkian, 2001.

MEIRELLES, Hely Lopes. Direito Municipal brasileiro. São Paulo: Malheiros, 2003.

MORAES, Alexandre de. Direito Constitucional. São Paulo: Atlas, 2006.

SANTANA, Jair Eduardo. Competências legislativas municipais. Belo Horizonte: Del Rey, 1998.

SANTOS, Mario Ferreira dos. Análise de temas socias. São Paulo: Editora LOGOS, 1962.

SEN, Amartya. Desenvolvimento como liberdade. São Paulo: Companhia das Letras, 2000 .

SOUZA, Washington Peluso Albino. Primeiras linhas de direito econômico. São Paulo: LTr, 1999.

VEIGA, José Eli da. Desenvolvimento Sustentável - o desafio do século XXI. Rio de Janeiro: Garamond, 2005. 